\section{PRACTICES AIM FOR BLACK BELT IN BUSINESS PERFORMANCE}

Software of Excellence looks set to revolutionise training across the dental profession with its recently launched Academy of Excellence - a new style of training programme based on the martial arts grading system.

Dental nurses, practice managers and reception staff can move through the training programme, achieving first white and then yellow belts, with each training scheme being tailored for each specific role. Practices meanwhile can achieve red and black belts when they improve business perfor- mance, with belts presented once the business achieves a target increase in revenue.

Modules can be studied via live online webinars delivered by Academy Training Consultants and eventually students will be able to login and study at any time of the day or night. In addition, training school classes have been set up throughout the country and practices can still opt for on-site training if they wish.

Training is based on getting the very best out of SoE's EXACT V11 software, which enables practices to automate various recall and administrative functions, massively increasing efficiency.

If you'd like to join the Academy of Excellence view the video at www.softwareofexcellence. com/uk/training/academy-ofexcellence.

\section{STRIPS WITH A GENTLE WHITENING FORMULA}

Providing patients with a more cost effective way to whiten their teeth, WhiteWash Professional Whitening Strips provide the ideal practice builder by expanding the range of quality treatments your practice has on offer.

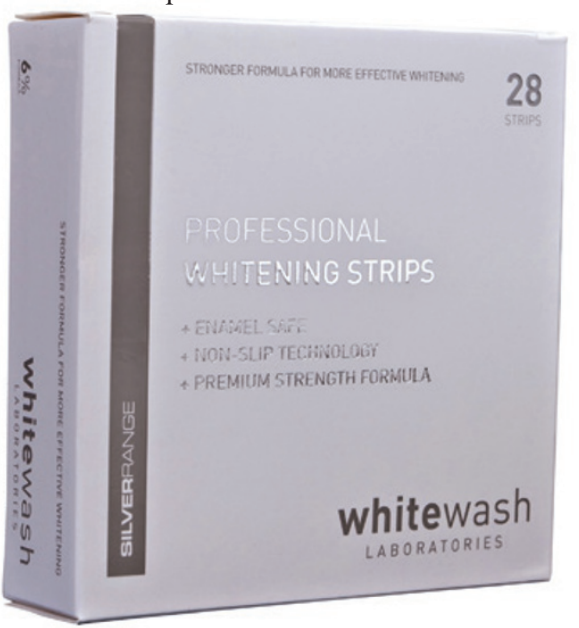

\section{OFFER INTEREST-FREE AND LOW COST LOANS}

Dental Finance, a team of experienced financial services professionals, enables practices to offer interest-free and low cost loans to patients for dental treatment. Offering patients monthly payment options makes treatments more affordable. Some of Dental Finance's practices report a 22\% or more rise in treatment plan take-up. There are benefits for practice turnover and cash flow and can attract more patients.

Businesses must now obtain authorisation from the Financial
The gentle whitening formula can be used by patients at home in conjunction with therapies provided in practice, or as a whitening treatment in its own right. Great for top-ups, more comfortable to use than trays and easily affordable, whitening strips appeal to a wide range of patients.

Boasting short application times and ease of use, WhiteWash Professional Whitening Strips enable you to provide a convenient and reliable service for a more efficient workflow.

With two strengths of strips available, enhance the service your practice delivers with Professional Whitening Strips from WhiteWash.

Ccall 0844686915 or visit www.whitewashstrips.com.

Conduct Authority before offering loans. The application process is more complicated than that operated previously by the Office of Fair Trading. Dental Finance is happy to provide all of the practices it currently supports, and any new practices, free assistance with the application process.

Dental Finance also offers free on-site training, e-training modules, application processing, full office support and marketing materials.

www.dentalfinance.co.uk

\section{NAOMI THE LIONESS IS CROWNED IN JUST ONE SESSION}

A Danish zoo is attracting attention with a spectacular dental procedure. The damaged carnassial tooth of a lioness in Ree Park Safari in Ebeltoft (near Aarhus) was restored using the CAD/CAM system CEREC. The Danish zoo wanted to use the benefits of the chairside system, which allows treatment in just one session, for its animal patient.

The veterinary team was faced with a few challenges when operating on the 12-year-old African lioness Naomi. Adult lions cannot be anesthetised for more than two to three hours, meaning that the entire procedure needed to be completed in that period of time. Since extracting such a large tooth is difficult and lions need the carnassial tooth to be able to bite, a root canal treatment was carried out and the tip of the carnassial tooth was fitted with a crown. The CEREC method allowed the entire treatment to be successfully completed in just a single procedure. Naomi recovered from the operation quickly without any complications and is now back to her old self.

Treating such a big cat shows the universality of CEREC. After treatment was successfully completed, everyone involved was clearly relieved.

For further information about CEREC call Sirona Dental Systems on 08450715040 or email info@ sironadental.co.uk.

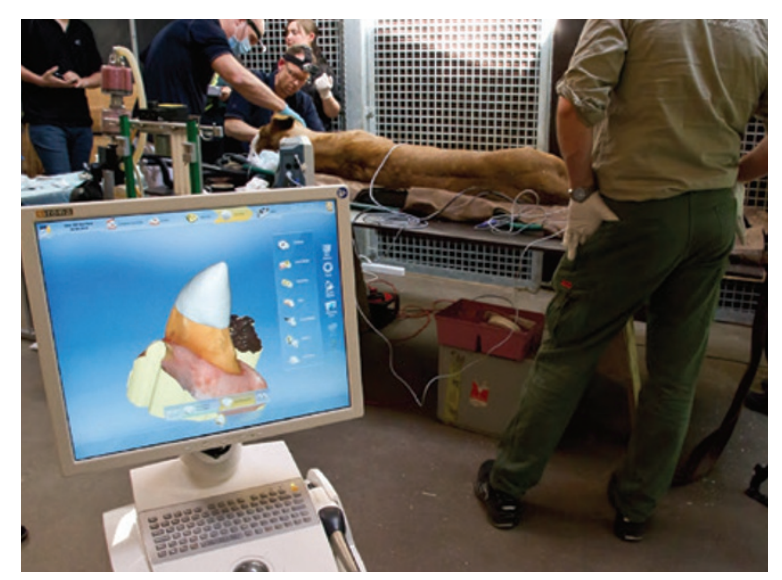

